
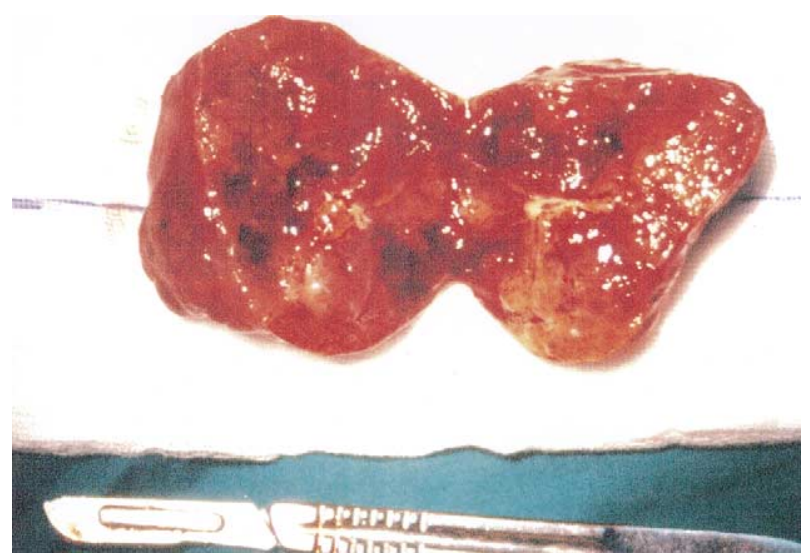

Figure 2. The well-encapsulated large tumor.

The patient's sex also differs. He was a man, and it is clearly stated in the literature that ectopic acromegaly is more often seen in women younger than 40 years. ${ }^{4}$

Unfortunately, the neuroendocrine tests cannot differentiate between ectopic GHRH secretion and pituitary adenoma. ${ }^{1}$ High $\mathrm{GH}$ plasma levels and excessive production of GHRH can be suggestive of ectopic secretion, with the exception of very rare cases of excessive GHRH of hypothalamic origin. ${ }^{2}$ The somatostatin receptor scintigraphy could have been an alternative diagnostic tool, but it was not performed in our case.

In inoperable cases or incomplete operations, octreotide seems to be effective. ${ }^{5}$ Surgical excision of the bronchial carcinoid tumor leads to a rapid decrease of GHRH and to a benign clinical course, as is also mentioned in other reports. ${ }^{1,2}$

\section{References}

1. Platts JK, Child DF, Meadows P, Harvey JN. Ectopic acromegaly. Postgrad Med J. 1997;73(860):349-51.

2. Glikson M, Gil-Ad I, Galun E, Dresner R, Zilberman Sh, Halperin Y, et al. Acromegaly due to ectopic growth hormone-releasing secretion by a bronchial carcinoid tumour. Dymanic hormonal responses to various stimuli. Acta Endocrinol (Copenhagen). 1991;125:366-71.

3. Faglia G, Arosio M, Bazzoni N. Ectopic acromegaly. Endocrinol Metab Clin North Am. 1992;21:575-95.

4. Caron Ph, Guittard J, Trouillas J, Salvador M, Bayard F. Acromégalie et tumeur carcinoïde bronchique. A propos d'une observation. Ann Endocrinol (Paris). 1992;53:158-61.

5. Harris PE, Bouloux BMG, Wass JA, Besser GM. Successful treatment by chemotherapy for acromegaly associated with ectopic growth hormone releasing hormone secretion from a carcinoid tumour. Clin Endocrinol. 1990;32:315-21.

\title{
Innominate artery transection in the setting of a bovine arch
}

\author{
Mireille A. Moise, MD, ${ }^{a}$ Vivian Hsu, BA, ${ }^{a}$ Benjamin Braslow, MD, ${ }^{b}$ and $\mathrm{Y}$. Joseph Woo, MD, ${ }^{a}$ Philadelphia, Pa
}

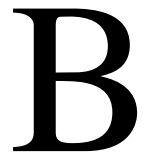

lunt trauma to the innominate artery is an infrequent but commonly fatal occurrence. We report a case of a patient with a bovine arch who underwent successful graft replacement of the innominate artery and reconstruction of the aortic arch under deep hypothermic circulatory arrest with retrograde cerebral perfusion.

\footnotetext{
From the Department of Surgery, Division of Cardiothoracic Surgery, ${ }^{\mathrm{a}}$ and the Department of Surgery, Division of Traumatology, ${ }^{\mathrm{b}}$ Hospital of the University of Pennsylvania, Philadelphia, Pa.

Received for publication Feb 16, 2004; revisions requested March 2, 2004; revisions received March 8, 2004; accepted for publication March 18, 2004.

Address for reprints: Y. Joseph Woo, MD, Department of Surgery, Division of Cardiothoracic Surgery, 6th Floor, Silverstein Building, Hospital of the University of Pennsylvania, 3400 Spruce St, Philadelphia, PA 19104 (Email: wooy@uphs.upenn.edu).

J Thorac Cardiovasc Surg 2004;128:632-4

$0022-5223 / \$ 30.00$

Copyright $\odot 2004$ by The American Association for Thoracic Surgery doi:10.1016/j.jtcvs.2004.03.006
}

\section{Clinical Summary}

A 46-year-old woman was brought to our trauma bay intubated with stable hemodynamics after a head-on motor vehicle collision. A chest x-ray film showed a widened mediastinum. A subsequent computed tomographic scan of the chest and aortogram revealed a contained traumatic pseudoaneurysm of the innominate artery in the setting of bovine arch anatomy (Figure 1). The patient also had a grade III liver laceration, bilateral rib fractures leading to bilateral pneumothoraces, and multiple lower extremity orthopedic injuries. She was taken on an emergency basis to the operating room. An external fixation device was placed to stabilize the right femur and to prevent further blood loss in that compartment. A baseline focused abdominal sonographic exam for trauma was then performed and repeated every 30 minutes to exclude the presence of intraperitoneal hemorrhage from the liver laceration in the setting of heparinization for cardiopulmonary bypass. A median sternotomy was performed, and cardiopulmonary bypass was initiated via ascending aortic and right atrial cannulation. Circulatory arrest with retrograde cerebral perfusion at a flow rate of 250 to $350 \mathrm{~mL} / \mathrm{min}$ and a central venous pressure of 21 to $23 \mathrm{~mm} \mathrm{Hg}$ was initiated at a core bladder temperature of $15^{\circ} \mathrm{C}$ (Figure 2, A). One gram of methylprednisolone sodium succinate (Solu-Medrol) was 

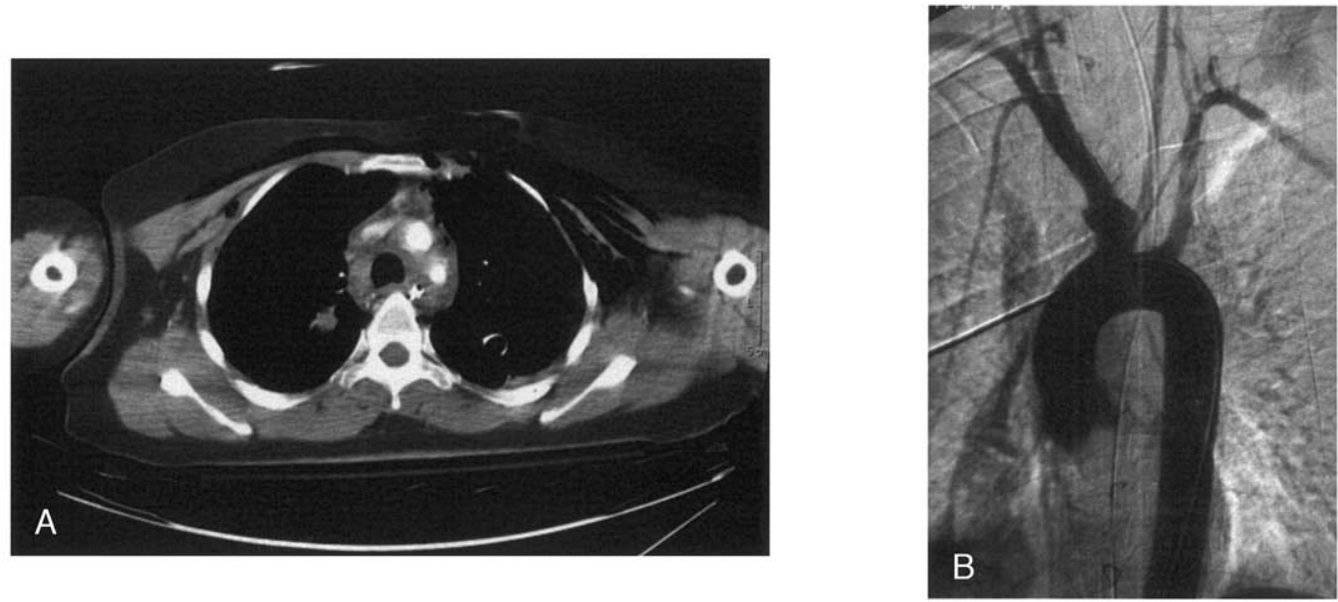

Figure 1. A, Computed tomographic scan image demonstrating a mediastinal hematoma and 2 trunks arising from the aortic arch, thus confirming bovine anatomy. B, Arch aortogram demonstrating injury at the takeoff of the left common carotid artery from the innominate artery.

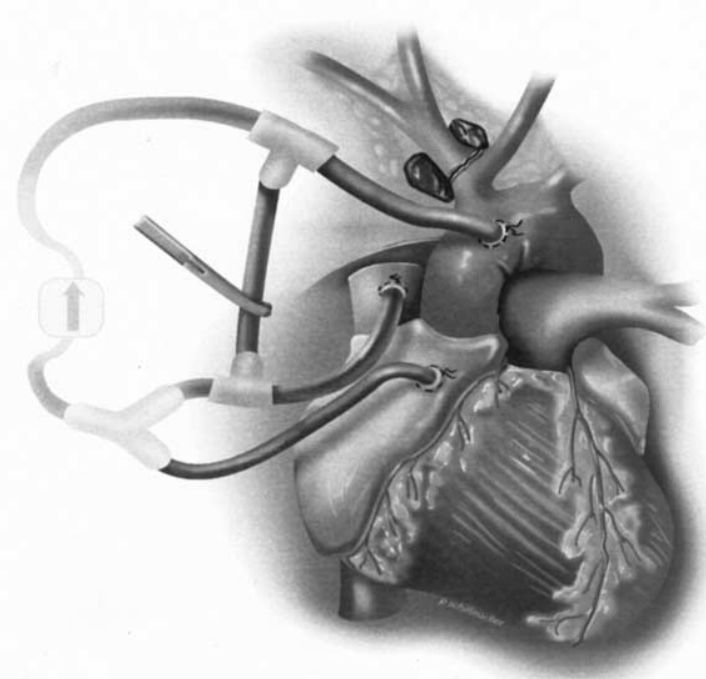

A

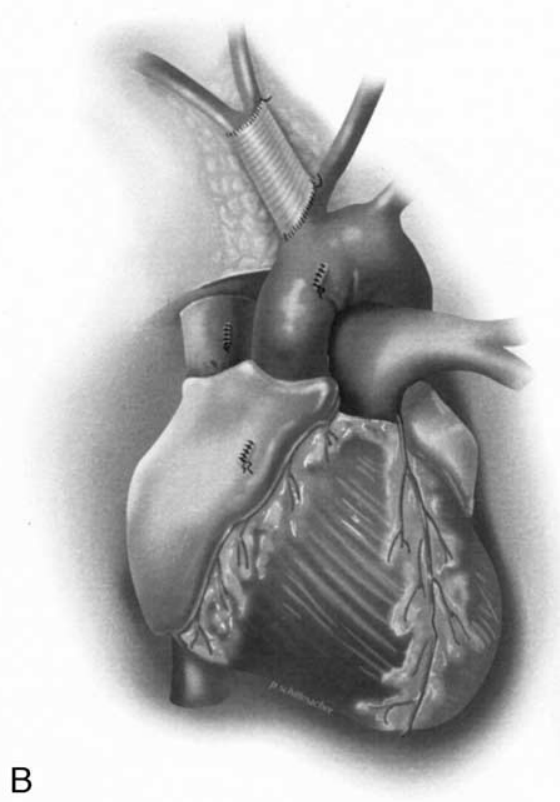

B

Figure 2. A, Vascular injury and the bypass circuit, which includes a superior vena cava cannula and arteriovenous bridge. $B$, Completed interposition graft.

given before the initiation of circulatory arrest. A complete $360^{\circ}$ circumferential intimal transection of the innominate artery at the takeoff of the left common carotid artery was found; it was held together by only a thin region of adventitia. After the innominate artery was excised back to healthy tissue, a Hemashield interposition graft (Meadox Medicals, Inc, Oakland, NJ) was then proximally anastomosed to the aortic arch and beveled to incorporate the ostium of the left common carotid artery. The graft was then anastomosed to the distal innominate artery at the bifurcation of the right subclavian and right common carotid arteries (Figure 2,
$B)$. On completion of the repair, the vascular system was extensively deaired, and antegrade perfusion was slowly reinitiated. The total hypothermic circulatory arrest and retrograde cerebral perfusion time was 50 minutes. Total cardiopulmonary bypass time was 204 minutes. The patient was taken to the intensive care unit, where she awoke neurologically intact several hours later. During her hospitalization, she underwent numerous orthopedic operations for her various injuries but was eventually discharged to an acute rehabilitation facility. At 6 months, the patient was at home doing well without evidence of any neurologic dysfunction. 


\section{Discussion}

The innominate artery is the second most common site of blunt injury to the aortic vessels, and blunt trauma is responsible for $35 \%$ of innominate artery injuries. ${ }^{1}$ Still, fewer than 100 cases of innominate artery injury caused by blunt trauma have been documented. ${ }^{2-4}$ An interesting association has been reported between this type of injury and bovine arch anatomy, in which the left common carotid originates from the innominate artery. Although there is only an $11 \%$ normal incidence of bovine arch anatomy, $29 \%$ of patients who have innominate artery disruption exhibit this anomaly, suggesting a predisposition to sustaining blunt injury at the innominate artery. ${ }^{1}$

One study recommended bypass of the injured segments of the arch before exploring the hematoma. ${ }^{4}$ This patient was placed on cardiopulmonary bypass before dissection of the hematoma. Cardiopulmonary bypass allows for greater visualization of the arch by decompressing the heart and provides more hemodynamic control. The risk of systemic anticoagulation in the setting of a grade III liver laceration and femur fracture did not escape us, and measures were taken to reduce the patient's risk by placement of an external fixator on the femur and by aggressive surveillance to detect early intraperitoneal bleeding. ${ }^{4}$

Because repair of this injury would likely disrupt most of the cerebral blood flow, the issue of cerebral perfusion had to be addressed. In this particular patient, retrograde cerebral perfusion was used in conjunction with deep hypothermia and circulatory arrest. Our center has had extensive experience with this technique in repair of complex arch reconstructions and acute type A dissections. Despite recent reports suggesting that retrograde cerebral perfusion may be linked to postoperative neurologic dysfunction, our experience is that the incidence of perioperative stroke is reduced. ${ }^{5}$ In addition, retrograde cerebral perfusion also extends greater latitude in operating time and cools the brain down roughly an additional $10^{\circ} \mathrm{C} .{ }^{5}$ Finally, it provides a deairing capacity by continually bathing the cerebral vascular system in blood. ${ }^{5}$

\section{References}

1. Graham JM, Feliciano DV, Mattox KL, Beall AC. Innominate vascular injury. J Trauma. 1982;22:647-55.

2. Johnson RH, Wall MJ, Mattox KL. Innominate artery trauma: a thirty year experience. J Vasc Surg. 1993;17:134-40.

3. Mauney MM, Casada DC, Kaza AK, Long SM, Kern JA. Management of innominate artery injury in the setting of bovine arch anomaly. Ann Thorac Surg. 2001;72:2134-6.

4. Jweied E, Fogelson B, Fishman D, Merlotti G. Blunt injury of the innominate artery associated with a bovine arch. J Trauma. 2002;52:1002-4.

5. Pochettino A, Cheung AT. Pro: retrograde cerebral perfusion is useful for deep hypothermic circulatory arrest. J Cardiothorac Vasc Anesth. 2003; 17:764-7.

\title{
Distal aortic arch aneurysm after endovascular stent graft repair for type B chronic aortic dissection
}

\author{
Claudio F. Russo, MD, Andrea Garatti, MD, Maurizio Puttini, MD, and Ettore Vitali, MD, Milan, Italy
}

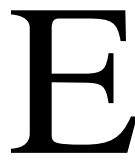

ndovascular stent grafting of the descending thoracic aorta has recently become a valid and safe alternative to surgical treatment of type B aortic dissection, even though it has been related to some complications, such as graft displacement, aortic injury, paraplegia, embolization, stroke, and left arm ischemia. In these cases, surgical management can be troublesome, particularly when displacement of the graft and proximal endoleak involve the aortic arch or the origin of the supra-aortic vessels.

\footnotetext{
From the Department of Cardiovascular Surgery, "A. De Gasperis,” Niguarda Ca'Granda Hospital, Milan, Italy.

Received for publication Jan 9, 2004; revisions requested Feb 5, 2004; revisions received Feb 12, 2004; accepted for publication March 16, 2004

Address for reprints: Andrea Garatti, MD, Department of Cardio-Thoracic Surgery, “A. De Gasperis," Ospedale Niguarda Ca'Granda, Piazza Ospedale Maggiore 3, 20162 Milan, Italy (E-mail: agaratti@tiscali.it).

J Thorac Cardiovasc Surg 2004;128:634-6

$0022-5223 / \$ 30.00$

Copyright $\odot 2004$ by The American Association for Thoracic Surgery

doi:10.1016/j.jtcvs.2004.02.035
}

\section{Clinical Summary}

A 68-year-old man came to the emergency room with cramplike pain in his right leg. He was obese and a heavy smoker, with a history of high blood pressure and mild chronic renal failure. General examination was unremarkable. Computed tomographic (CT) scan showed an extensive chronic type B aortic dissection with an aortic diameter greater than $6 \mathrm{~cm}$. Transesophageal echocardiogram confirmed the diagnosis and showed a wide intimal tear with no involvement of the left subclavian artery. Because of stable conditions and the lack of complications, the patient did not undergo urgent surgery but was managed medically. At aortography, aortic dissection extended from the distal aortic arch to the femoral vessels; all visceral branches arose from the true lumen, but both superior mesenteric and left renal arteries were partially compressed by the false lumen. An anomalous origin of the supraaortic vessel was detected with a common origin of the left carotid and subclavian arteries (left brachiocephalic trunk). Considering the large dimension of the thoracic aorta and the risk of visceral vessel malperfusion, the patient underwent successful endovascular exclusion of the intimal tear with a Thoracic Excluder (W. L. Gore \& Associates, Inc, Flagstaff, Ariz; $40 \mathrm{~mm} \times 15 \mathrm{~cm}$ ). The stent graft was placed distally from the origin of the arch vessels. 